\title{
The Spirituality Questionnaire: Core Dimensions of Spirituality
}

\author{
Jochen Hardt ${ }^{*}$, Sonja Schultz ${ }^{1}$, Carola Xander ${ }^{2}$, Gerhild Becker ${ }^{2}$, Malgorzata Dragan ${ }^{3}$ \\ ${ }^{1}$ Medical Psychology and Medical Sociology, Clinic for Psychosomatic Medicine and Psychotherapy, \\ University Medical Center, University of Mainz, Mainz, Germany \\ ${ }^{2}$ Psychotherapy, University Medical Center, University of Mainz, Mainz, Germany \\ ${ }^{3}$ Faculty of Psychology, University of Warsaw, Warsaw, Poland \\ Email: "hardt@mail.uni-mainz.de
}

Received September $2^{\text {nd }}$, 2011; revised October $9^{\text {th }}$, 2011; accepted November $18^{\text {th }}$, 2011

\begin{abstract}
Various approaches are used to assess spirituality via questionnaires, ranging from one-dimensional scales to highly multidimensional models. For the present investigation, a-in spirituality research unorthodox -factor analytic method was chosen: principal axis analysis with oblique rotation. An item collection was examinated and cross-validated via internet. The spirituality questionnaire contains four dimensions: belief in God, search for meaning, mindfulness, and feeling of security. They present with high internal consistencies. The factorial structure of the four dimensions was confirmed. Based on the better fit of this method of extraction the authors assume that these dimensions may depict the concept of spirituality more precisely than the previously used factor analytic methods, i.e. the principal component analysis (PCA) with orthogonal rotation.
\end{abstract}

Keywords: Questionnaire Assessment; Religiousness; Spirituality; Mindfulness

\section{Introduction}

Psychological research on spirituality and religiousness was strongly influenced by some of Allport's early work. He distinguished between internal and external religiousness (IR vs. ER), "the extrinsically motivated individual uses his religion, whereas the intrinsically motivated lives his” (Allport \& Ross, 1967). When the IR-ER concept was related to mental health, it was found that internal religiousness was positively associated with mental health, external religiousness negatively (James \& Wells, 2003). Examining more complex models of religiousness shows that various aspects of spirituality are generally positively associated with mental health and well-being, i.e. any form of belief seems to help patients (Mohr \& Huguelet, 2004; Mofidi, Devellis, et al., 2006; Mofidi, DeVellis, et al., 2007). Studies on the influence of religiousness and spirituality on physical health were mainly performed on cancer patients and show that religiousness or spirituality is important for the vast majority of patients (Balboni, Vanderwerker, et al., 2007). Gall (2011) states that "religious and spiritual beliefs in relation to one's connection to a greater significance can aid in the creation of life meaning and purpose. Spiritual beliefs help individuals make sense of suffering”.

Lawler-Row and Elliott interpreted this in a way that religiosity and spirituality provide an overarching interpretive scheme for making sense of live. "Every person has the 'will' to seek meaning in life or to achieve purpose in life" (Ishida, 2011). Furthermore positive affected spiritual interaction has strong influence on the patients quality of life, and existential well-being is strongly related to all outcome health measures (Lawler-Row \& Elliott, 2009). Even the effectiveness of psychotherapeutical treatment can depend on "the match or mis-

\footnotetext{
*Corresponding author.
}

match between a client's religious or spiritual (R/S) beliefs and the type of psychotherapy." (Worthington, Hook, et al., 2011)

For a patient who believes in religion or spirituality, a psychologist discounting these issues as not important may not be the right therapist. As Hall (2010) states “The psychologist's position on spirituality is not irrelevant to setting the tone of the practice enviroment. From those who endorse spirituality to those who reject it, there will be an impact in a myriad of ways" (p. 49). In his study on Mestizo spirituality, Cervantes (2010) comes to a similar conclusion, noting that "the interested (therapeutic) practitioner (should) be familar with Mexican/ Mexican American populations and the related indigeneous spiritual background” (p. 536).

Today, with the increasing secularisation in many western countries, the authors see the focus in society moving away from religiousness towards spirituality. In spite of an ancient tradition connecting science, medicine and religiousness, there is not much doubt that modern western medicine has not concentrated much on the religious and spiritual needs of patients but has widely left this field to alternative medicine (Koenig, McCullough, et al., 2001). However, there recently are some large studies concerning the impact of spirituality and religiousness on physical health. As Nicholson et al. state in an international comparative study "There are extensive data linking religious involvement with better health” (p. 1). Using multilevel logistic regression models, Nicholson et al. depicted religious participation as an indicator for the individual medical condition (Nicholson, Rose, et al., 2010). Apart form spirituality, at least a tendency is visible in medicine that for some special patient groups it becomes realized that a mechanical model alone does not suffice to explain the patients complaints (e.g. chronic fatigue: Van Houdenhove \& Luyten, 2011), others have shown that the coherence of the meaning system in mind is 
lower in psychiatry patients than in psychotherapists (Löffler, Knappe, et al., 2010).

Apart from Allport's concept of the IR-ER religious orientation, a variety of questionnaires has been developed to measure spirituality and/or religiousness (Monod, Brennan, et al, 2011). Some consider it a one-dimensional construct (Koenig, Parkerson, et al., 1997) while others use a multidimensional approach. Considering the widely individual character of spirituality, the authors think that a multidimensional approach is necessary to capture the various aspects of spirituality adequately. Büssing (2006), for example, identified 24 dimensions in religiousness and spirituality. Among others, the latter comprises "asking for the meaning of life", "transcendence", "search for insight and wisdom”, "prayer", "trust in God". However, it must be stated, that there is not much congruence between the various approaches. One possible explanation would be in the statistical method used. The vast majority of researchers relied on factor analysis to develop the dimensions. In doing so, research on religiousness and spirituality has almost totally applied principal component analysis (PCA) with orthogonal rotation. It has been shown that PCA is not ideal for extraction, i.e. it overestimates the item loadings and results in unstable models (Gorsuch, 1997). Orthogonal rotation means that the factors are forced to be uncorrelated. With respect to the dimensions of spirituality this assumption maybe questionable (Heszen-Niejodek, 2003). It would be more realistic to assume some positively correlated factors.

Hence, the aim of the present paper was to develop a multidimensional questionnaire on spirituality using a different factor analytic method that maybe more suitable for a model describing spirituality, i.e. principal axis factoring with oblique rotation. Here, the communality of each item is first estimated by the highest correlation to any other item. The extracted factors are later rotated without any fixed angles between them so that the assumption of independent factors is no longer necessary.

For this purpose, the items of the Kwestionariusz Samoopisu (Heszen-Niejodek, 2003) were translated from Polish into German by a native German speaker and supplemented by other items reflecting various aspects of spirituality. The supplemented item set was then translated back into Polish by a native Polish speaker. Those items originally formulated in German were translated back into German again by the native German speaker. The back translations were checked by JH and MD and modified to become identical in both languages and comprehensive for our understanding of spirituality. The thus developed item pool comprises items about belief in God, search for meaning, mindfulness and consciousness and feeling of security.

A pilot study was performed on medical students. Although the pilot questionnaire was long (61 items), it was well accepted. Feedback from the students was largely positive, it was said that it was interesting to fill out. Hence, all 61 items were applied to sample 1 via internet. Factor analysis resulted in four dimensions: 1) belief in God; 2) search for meaning; 3) mindfulness and 4) feeling of security, comprising 27 of the 61 original items. No other scale could be constructed out of the item pool that contained at least five items. For the 27 items, the questionnaire was cross-checked again to ensure that every item was clearly phrased in a modern everyday language and that it focused on one single topic only. This was done to discover precisely which aspects of spirituality constitute our di- mensions. If necessary, minor reformulations of the items were performed again. The questionnaire was then shortened to 20 items, retaining only those 5 items for each dimension that were most specific. All scales were to be answered on a five-point Likert scale with the categories "not true at all", "hardly true", "don't know" "rather true” and "absolutely true". This new questionnaire was then cross-validated in a new sample of 500 participants via internet again. It can be viewed at http://www. screening4you.de

\section{Method}

\section{Samples}

Subjects were asked via Internet to fill out a questionnaire containing about 280 items. They were registered participants at a company that mainly performs marketing research. The ethic commissions of the University of Düsseldorf and for Rheinland-Pfalz approved the project (Nr. 3063 and 6281). Data collections were performed in January and October 2008 by a professional marketing institute (http://www.linequest.de). Participants were about 40 (sample 1) to 45 (sample 2) years old on average, and about 50\% female (see Table 1). The majority of participants of both samples were living in a partnership. About $48 \%$ in the first sample and $61 \%$ in the second sample were members of one of the German Christian churches. The differences between sample 1 and 2 are likely to be largely an effect of age.

\section{Procedure}

The spirituality questionnaire was located in the middle of the item set. Participants registered at a commercial company to fill out online questionnaires, mostly for marketing research. They were informed that the present questionnaire served research purposes and that the authors were interested in mental health in combination with various life circumstances. During data collection, information was put onto the homepage of the University of Mainz to enable participants to verify the scientific background of the study. Participants received a compensation of about $€ 4.30$ for filling out the questionnaire. Even if the questionnaire was long, some individual feedback was rather positive, it was told that it was interesting to fill out the questionnaire. Particularly the questions about spirituality and about childhood received positive evaluation.

\section{Statistical Analysis}

The items of the spirituality questionnaire were coded from zero to four. Sub score scales of the spirituality questionnaire were calculated as the mean of their respective items. There were no missing items in the internet surveys, because the programme prompted the respondents for an answer when an item was left open.

The first step of the analysis was to compare convergent and discriminant item correlations in both samples (for a detailed description of the methods, see Hardt, Petrak, et al., 2003). In a second step, item and sub score means between samples 1 and 2 were compared via t-tests. Finally, correlations between the subscales were computed. The alpha level for all statistical tests was set to .01 (two-tailed). Hence, effect sizes for mean comparisons (Cohen, 1988) of $\mathrm{d}<.15$ were non-significant in the present sample. This alpha level was set to balance statistical 
Table 1.

Sample description.

\begin{tabular}{|c|c|c|c|}
\hline & Sample 1 & Sample 2 & \\
\hline $\mathrm{N}$ & 500 & 500 & Test for differences \\
\hline Gender (\% female) & 55.4 & 50.0 & $x_{(1)}^{2}=2.93, p=.087$ \\
\hline Age: $\bar{x}$ (sd) & $39.3(11.2)$ & $44.8(16.1)$ & $\mathrm{t}_{998}=6.27, p<.001$ \\
\hline \multicolumn{4}{|l|}{ Confession (\%) } \\
\hline Christian & 48.2 & 60.8 & \\
\hline Other & 2.8 & 1.6 & \\
\hline None & 49.0 & 37.6 & $x_{(4)}^{2}=16.42, p<.001$ \\
\hline \multicolumn{4}{|l|}{ Nationality (\%) } \\
\hline German & 94.2 & 97.4 & \\
\hline Other & 5.8 & 2.6 & $x_{(2)}^{2}=6.36, p=.012$ \\
\hline Living in Partnership (\%) & 84.0 & 70.0 & $x_{(2)}^{2}=27.67, p<.001$ \\
\hline \multicolumn{4}{|l|}{ Job (\%) } \\
\hline High grade professional & 7.4 & 4.2 & \\
\hline Lower grade professional & 17.8 & 30.2 & \\
\hline Skilled non-manual employee & 38.4 & 33.0 & \\
\hline Skilled manual employee & 3.4 & 5.2 & \\
\hline Partly skilled worker & 20.0 & 10.8 & \\
\hline Unskilled labourer & 6.0 & 6.2 & \\
\hline Housewife/ housemen & 7.0 & 10.4 & $x_{(6)}^{2}=41.46, p<.001$ \\
\hline
\end{tabular}

and clinical significance. Even if $d<.15$ is not a common standard, the authors think it made sense to set the significance at this level in the present study. It means, that in a two group comparison about $10 \%$ of the variance are different (Cohen, 1988: p. 20). Trends were not interpreted. Calculations were performed using ITAMIS (Kohr, 1978), SPSS 14.0 (SPSS) and STATA 11.0 (StataCorp, 2009).

\section{Results}

\section{Scale Structure}

As a result, the four subscales were confirmed as originally designed: 1) belief in God, 2) search for meaning, 3) mindfulness, 4) feeling of security. The subscales presented with good reliabilities (.78 $\leq$ Cronbachs $\alpha \leq .97)$ and medium positive intercorrelations $(.26 \leq \mathrm{r} \leq .52)$. All items except two had higher convergent than discriminant correlations. Item 13 ("I try to expand my soul”) had one marginally higher value on a foreign scale in sample 2 (see Table 2). Differences between the two samples on the structural level were minimal. Except for the scale "belief in God", the convergent correlations as well as Cronbach's alpha were smaller in sample 2. The scale "search for meaning" had a Cronbach's alpha of about .78 in sample 2, which was considerably lower than in sample 1 . The other scales represented with good to excellent internal consistencies in both samples.

\section{Mean Differences}

The means of the scales "belief in God", "search for meaning" and "mindfulness" did not differ significantly between the two samples. However, in the scale "belief in God", two items had significantly lower means in sample 2 (item 12 "My belief in God helps me to get along with difficult situations in life", $t$ $=4.42, p=.001$; item 3 "I turn to God", $\mathrm{t}=3.46, p=.001$. In item 3 the significance of the difference is attributable to the shortening of the item). Likewise, in the scale "search for meaning", two items had significantly lower means in sample 2 (item 7 "My life is a constant searching and questioning", $\mathrm{t}=$ 6.83, $p<.001$; item 13 "I try to expand my soul", $\mathrm{t}=4.65, p$ $<.001$ ), another item had a significantly higher mean (item 9 "I look for insight and coherence in life”, $\mathrm{t}=4.33, p<.001$ ). Likewise, in the scale "mindfulness", one item had a significant lower mean in sample 2 (item 16 "I try to help others", $\mathrm{t}=6.23$, $p<.001)$. The scale "feeling of security" had a significantly higher mean in sample $2(\mathrm{t}=4.09, p<.001)$, with an effect size of $d=.25$. On this scale, all but one items showed significantly higher values in sample 2 (items 6, 5, 8, 19; see Table 3).

\section{Age- and Gender Effects}

Computing a regression analysis, for the subscale "belief in God", an age effect was found $(\beta=0.12 ; \mathrm{t}=3.71 ; p<.001$; Table 3), indicating that older persons have a stronger belief in 
Table 2.

Item parameter.

\begin{tabular}{|c|c|c|c|c|c|c|c|c|c|}
\hline \multirow[b]{2}{*}{ Item } & \multirow[b]{2}{*}{ Abbreviation } & \multicolumn{4}{|c|}{ Sample 1} & \multicolumn{4}{|c|}{ Sample 2} \\
\hline & & God & SfM & Min & Sec & God & SfM & Min & Sec \\
\hline & Belief in God & .97 & & & & .96 & & & \\
\hline 15 & I trust in God & .90 & .35 & .25 & .27 & .93 & .47 & .23 & .41 \\
\hline 12 & My faith helps to cope w. problems & .93 & .41 & .24 & .28 & .92 & .47 & .26 & .42 \\
\hline 18 & I trust in my faith for decisions & .90 & .43 & .25 & .31 & .81 & .50 & .25 & .48 \\
\hline 14 & I feel the love of God & .93 & .46 & .23 & .38 & .89 & .53 & .26 & .47 \\
\hline \multirow[t]{2}{*}{2} & I feel that God is my friend & .90 & .44 & .27 & .44 & .88 & .46 & .23 & .41 \\
\hline & Search for meaning & & .93 & & & & .78 & & \\
\hline 7 & My life means searching and asking & .32 & .73 & .28 & .24 & .11 & .39 & .19 & -.05 \\
\hline 9 & I look for insight and coherence & .33 & .79 & .31 & .31 & .22 & .55 & .46 & .30 \\
\hline 10 & I try to open my mind & .36 & .81 & .34 & .46 & .35 & .63 & .36 & .43 \\
\hline 13 & I try to expand my soul & .46 & .87 & .35 & .40 & .64 & .61 & .36 & .43 \\
\hline \multirow[t]{2}{*}{3} & I search for the spirit & .47 & .86 & .33 & .43 & .51 & .62 & .35 & .31 \\
\hline & Mindulfness & & & .89 & & & & .83 & \\
\hline 17 & I try to deal consciously with others & .25 & .22 & .71 & .34 & .20 & .34 & .72 & .20 \\
\hline 1 & I deal consciously with environment & .26 & .32 & .74 & .39 & .17 & .30 & .51 & .17 \\
\hline 16 & I try to help others & .18 & .29 & .74 & .32 & .27 & .42 & .67 & .27 \\
\hline 11 & I try to be patient and tolerant & .24 & .28 & .75 & .42 & .16 & .32 & .60 & .16 \\
\hline \multirow[t]{2}{*}{4} & I try to be empathetic with others & .17 & .40 & .71 & .44 & .21 & .40 & .65 & .21 \\
\hline & Feeling of Security & & & & .88 & & & & .83 \\
\hline 6 & I feel peace deep inside me & .42 & .42 & .49 & .74 & .33 & .25 & .26 & .66 \\
\hline 7 & My life is peace and joy & .29 & .22 & .42 & .71 & .27 & .24 & .30 & .71 \\
\hline 8 & I feel one with the world & .40 & .37 & .37 & .69 & .38 & .39 & .30 & .64 \\
\hline 19 & I see a friendly world around me & .17 & .30 & .26 & .70 & .29 & .19 & .32 & .56 \\
\hline 20 & I feel there is a lot of love in the world & .19 & .42 & .36 & .73 & .52 & .41 & .37 & .55 \\
\hline
\end{tabular}

God than younger ones. For the subscale "search for meaning", an age effect was also found $(\beta=0.09 ; \mathrm{t}=2.77, p=.006)$. Though small, it also indicates higher values on this scale for older persons. Additionally, a sample effect was found $(\beta=$ $0.11 ; \mathrm{t}=3.35, p=.001$ ), demonstrating higher values on this scale in the first sample. Age also affected the values of the subscale "mindfulness" significantly $(\beta=0.11 ; \mathrm{t}=3.35, p$ $=.001$ ), again older persons exhibited higher values. For the subscale "feeling of security", two factors have significant influence: age $(\beta=.22 ; \mathrm{t}=7.18, p<.001)$, indicating higher values for older persons and sample $(\beta=0.08$; $\mathrm{t}=2.62, p=.009)$, demonstrating higher values for people of the sample 2. Membership of a Christian Church is highly associated with belief in God, but marginally with the other scales (Table 4).

\section{Discussion}

In general, the spirituality questionnaire shows similar item characteristics in both samples. Convergent item-test score correlations were good for all items but two, and discriminant correlations were considerably lower for almost all items. From a test-statistical view, the questionnaire demonstrates good qualities. The first two scales of the spirituality questionnaire, "belief in God" and "search for meaning" can be regarded as core dimensions of spirituality, as understood by most researchers. The scale "belief in God" represents the traditional western concept of spirituality. The phrasing of the items of the scale "belief in God" in this questionnaire has the advantage of not specifying which God the participant believes in, i.e. followers of all religions that incorporate deism are included.

A second scale of the spirituality questionnaire is the quest for meaning and sense in life as comprised by the scale "search for meaning". The search for meaning is an essential question for self-reflecting individuals (Fromm, 1950). In psychotherapy, it was Frankl (1964) who emphasised the importance of searching for meaning. He described the "noetic" dimension as the "spiritual" core of man's personality. Within this dimension, human beings find their quest for a meaningful existence, and the ability to overcome existential suffering. In the field of spirituality research, the quest approach was established by 
Table 3.

Means of the subscales and items.

\begin{tabular}{|c|c|c|c|c|c|c|}
\hline & \multicolumn{2}{|c|}{ Sample 1} & \multicolumn{2}{|c|}{ Sample 2} & \multirow[b]{2}{*}{$t_{998}$} & \multirow[b]{2}{*}{$p$} \\
\hline Scale and items & $\bar{x}$ & sd & $\bar{x}$ & sd & & \\
\hline I trust in God & 1.43 & 1.43 & 1.13 & 1.35 & 3.46 & $p=.001$ \\
\hline My faith helps me to cope w. problems & 1.48 & 1.46 & 1.18 & 1.33 & 3.42 & $p=.001$ \\
\hline I trust in my faith for decisions & 1.22 & 1.34 & 1.09 & 1.24 & 1.62 & $p=.106$ \\
\hline I feel the love of God & 1.29 & 1.33 & 1.15 & 1.26 & 1.73 & $p=.084$ \\
\hline I feel that God is my friend & 1.30 & 1.40 & 1.43 & 1.35 & 1.47 & $p=.141$ \\
\hline Search for meaning & 2.12 & 1.08 & 1.99 & 0.84 & 2.15 & $p=.032$ \\
\hline I look for insight and coherence & 2.34 & 1.22 & 2.64 & 0.97 & 4.33 & $p<.001$ \\
\hline I try to open my mind & 2.13 & 1.22 & 2.22 & 1.13 & 1.24 & $p=.215$ \\
\hline I try to expand my soul & 1.91 & 1.26 & 1.54 & 1.23 & 4.65 & $p<.001$ \\
\hline I search for the spirit & 1.84 & 1.22 & 1.66 & 1.22 & 2.29 & $p=.022$ \\
\hline Mindfulness & 2.98 & 0.68 & 2.95 & 0.63 & 0.80 & $p=.424$ \\
\hline I try to deal consciously with others & 2.90 & 0.79 & 2.98 & 0.81 & 1.66 & $p=.097$ \\
\hline I deal consciously with environment & 2.96 & 0.76 & 2.96 & 0.76 & 0.04 & $p=.967$ \\
\hline I try to help others & 3.19 & 0.72 & 2.87 & 0.90 & 6.23 & $p<.001$ \\
\hline I try to be patient and tolerant & 2.94 & 0.88 & 3.02 & 0.78 & 1.48 & $p=.140$ \\
\hline Feeling of security & 1.71 & 0.93 & 1.93 & 0.81 & 4.09 & $p<.001$ \\
\hline I feel peace deep inside me & 1.73 & 1.17 & 2.01 & 1.01 & 4.03 & $p<.001$ \\
\hline My life is peace and joy & 1.98 & 1.15 & 2.25 & 0.98 & 4.09 & $p<.001$ \\
\hline I feel one with the world & 1.40 & 1.11 & 1.77 & 1.02 & 5.41 & $p<.001$ \\
\hline I see a friendly world around me & 1.22 & 1.34 & 1.09 & 1.24 & 4.14 & $p<.001$ \\
\hline I feel there is a lot of love in the world & 1.74 & 1.09 & 1.65 & 1.15 & 1.19 & $p=.236$ \\
\hline
\end{tabular}

Table 4.

Pearson-Correlations among the subscales and between the subscales and gender, age and membership of a Christian Church.

\begin{tabular}{|c|c|c|c|c|c|c|c|c|}
\hline & \multicolumn{4}{|c|}{ Sample 1} & \multicolumn{4}{|c|}{ Sample 2} \\
\hline & God & SfM & Min & Sec & God & SfM & Min & Sec \\
\hline Mindfulness & .67 & .39 & & & .26 & .46 & & \\
\hline Security & .36 & .42 & .45 & & .47 & .39 & .40 & \\
\hline Age & .03 & .06 & .09 & .25 & .18 & .12 & .05 & .22 \\
\hline Gender & .10 & .06 & .09 & -.17 & -.01 & .00 & .16 & .05 \\
\hline Church & .48 & .21 & .01 & -.05 & .47 & .14 & .06 & .13 \\
\hline
\end{tabular}

$|\mathrm{r}|>.12$ is significant at $p<.01$. 
Batson and Ventis (1985) to assess to what degree a religious person incorporates an open-ended responsive dialogue with existential questions raised by the contradictions and tragedies of life.

Mindfulness, the third subscale, assesses the conscious perception of others and the environment. The concept is reflected in various eastern reliagions, particularly in Buddhism (Suzuki, Fromm, et al., 1972). In recent time, it has found some entrance into psychotherapy research (Kabat-Zinn, 1990; Lakey, Campbell, et al., 2007). In brief, it describes the development of equanimity (one of the four divine states in buddhism), overcoming emotional reactivity and developing friendliness, tolerance, gentleness, placidity, acceptance and (Grossmann and Grossmann, 2007). Mindfulness also includes conscious and attentive contact with others. Various questionnaires exist to assess mindfulness, i.e. the Kentucky Inventory of Mindfulness Skills (KIMS: Baer, Smith, et al., 2004), the Freiburger Fragebogen zur Achtsamkeit (FFA: Walach, 2006) and the Mindful Attention and Awareness Scale (MAAS: Brown, 2003). There is some evidence that mindfulness is linked with physical as well as mental health. Carlson and Brown (2005) found negative correlations of the MAAS with mood disturbances and stress. In a study of Carmody and colleagues (2008), increases in mindfulness and spirituality were associated with decreases in psychological distress and reported medical symptoms. Furthermore, programmes on mindfulness based stress reduction aim to improve chronic disorders like pain, cancer, depression, anxiety and overall quality of life in patients as well as in non-clinical groups (Grossman, Niemann, et al., 2004; Flugel, Colle, Vincent, et al., 2010). However, further research assessing long-term outcomes are needed. Kohls (2009) identified two mechanisms that are mainly imortant for the positive effects: equanimity and overcoming emotional reactivity.

Finally, the fourth subscale, "feeling of security", characterises a feeling of safety and trust in the world, a feeling of being at home in the world. In developmental psychology, Erikson (1995) drew a parallel to our scale with his concept of "sense of basic trust". Due to Erikson, a child develops this "sense of basic trust" within the first few years of life as a foundation for further development of personality. With "feeling of security", a dimension found entrance into the questionnaire that seems to be conceptually underdeveloped in western culture.

The authors observed small but consistent age-effects; the older the respondent was, the higher the reported spirituality. Effects were relatively strong for the feeling of security $(.22 \leq \mathrm{r}$ $\leq .25$ ), but considerably smaller for most other dimensions (see table 4). These results are consistent with earlier studies (e.g.: Idler, Musick, et al., 2003; Flannelly \& Galek, 2006). They point to the likelihood that spirituality tends to increase during later adulthood (Moberg, 2005).

Gender effects were also small, and furthermore inconsistent. The latter was surprising because previous studies have suggested that, regardless of a person's religious identification, women tend to be more religious and spiritual than men (Flannelly \& Galek, 2006). However, our findings appear to provide a challenge to this often accepted notion of gender differences, as others recently have (Büssing, 2006).

The present study has several limitations. 1) The four extracted dimensions by no means represent the huge variety of aspects contributing to the concept spirituality. They are factor-analytically derived, and an old critique of factor analysis already states: "In factor analysis you only get out what you put in before” (Eysenck 1985, cited after Schumann, 2009). This means that although items describing many facets of spirituality were included, it is possible that some aspects were not represented by at least five items and did not constitute a separate factor. Adding more questions about these aspects to the data set would probably have led to an additional factor. Despite our endeavour to apply techniques that correspond with the subject (PAF with oblique rotation), the item selection remained subjective. Indeed, the authors were surprised that only four factors could be retained from our relatively large item pool. 2) The present data were collected via internet. Sample 1 was not representative while sample 2 was representative concerning age and gender. It is still not known how Internet users differ from the general population. This may have caused a bias in the results. 3) The attempt to assess spirituality utilising a questionnaire may be regarded dubiously by other researchers. It can be argued that this field is intrinsically idiosyncratic and may not be subject to quantitative research. On the other hand, the present data demonstrate that there is considerable congruence between different subject groups, otherwise such a clear factor structure would not have emerged.

With the limitations given above, the authors believe that the spirituality questionnaire represents a valid instrument to assess four core dimensions of spirituality. Even in the event of weak loadings, which was not the case in the present investigation, the sample sizes were large enough to give valid results. All scales present with good reliability and a clear structure almost identical in the two samples. The questionnaire is easy to apply, and respondents usually have no problems filling it out. Items are clearly worded and the answering categories seem adequate. The authors hope that the spirituality questionnaire will encourage others to do research in a field which is important for many patients but has been almost overlooked in medical research.

\section{Acknowledgement}

This work was supported in part by the Heigl-Stiftung Düsseldorf and by the Köhler Stiftung Essen.

\section{REFERENCES}

Allport, G. W., \& Ross, J. M. (1967). Religious orientation and prejustice. Journal of Personality and Social Psychology, 5, 432-443. doi:10.1037/h0021212

Baer, R. A., Smith, G. T., et al. (2004). Assessment of mindfulness by self-report: The Kentucky inventory of mindfulness skills. Assessment, 11, 191-206. doi:10.1177/1073191104268029

Balboni, T. A., Vanderwerker, L. C., et al. (2007). Religiousness and spiritual support among advanced cancer patients and associations with end-of-life treatment preferences and quality of life. Journal of Clinical Oncology, 25, 555-560. doi:10.1200/JCO.2006.07.9046

Daniel Batson, \& Larry Ventis, W. (1985). Misconception of quest: A reply to hood and morris. Review of Religious Research, 26, 398-407. doi:10.2307/3511053

Brown, K. W., \& Ryan, M. (2003). The benefits of being present: The role of mindfulness in psychological well-being. Journal of Personality and Social Psychology, 84, 822-848. doi:10.1037/0022-3514.84.4.822

Büssing, A. (2006). Spirituality-what are we talking about? [Spiritualität-Worüber reden wir?] In A. Büssing, T. Ostermann, \& Matthiesen, P. F. (Eds.), Spirituality, disorder and cure-Meaning and expression of spirituality in medicine [Spiritualität, Krankheit 
und Heilung-Bedeutung und Ausdrucksformen der Spiritualität in der Medizin] (pp 11-24). Frankfurt am Main: VAS-Verlag.

Büssing, A., Ostermann, T., \& Matthiesen, P. F. (2006). Distinct expressions of vital spirituality. Journal of Religion and Health, 46, 267-286.

Carlson, L. E., \& Brown, K. W. (2005). Validation of the mindful attention awareness scale in a cancer population. Journal of Psychosomatic Research, 58, 29-33. doi:10.1016/j.jpsychores.2004.04.366

Carmody, J., \& Baer, R. A. (2008). Relationships between mindfulness practice and levels of mindfulness, medical and psychological symptoms and well-being in a mindfulness-based stress reduction program. Journal of Behavioral Medicine, 31, 23-33.

doi:10.1007/s10865-007-9130-7

Cervantes, J. M. (2010). Mestizo spirituality: Toward an integrated approach to psychotherapy for Latina/OS. Psychotherapy (Chic), 47, 527-539. doi:10.1037/a0022078

Cohen, J. (1988). Statistical power analysis for behavioural sciences. Hillsdale, NY: Lawrence Erlbaum Associates.

Erikson, E. H. (1998). The life cycle completed. New York, NY: W W Northon \& Co. [Der vollständige Lebenszyklus (1995). Frankfurt am Main: Suhrkamp].

Flannelly, K. J., \& Galek, K. (2006). Discipline and sex differences in religiosity and spirituality among health care professionals. Psychological Reports, 99, 803-804.

Flugel Colle, K. F., Vincent, A., et al. (2010). Measurement of quality of life and participant experience with the mindfulness-based stress reduction program. Complementary Therapies in Clinical Practice, 16, 36-40. doi:10.1016/i.ctcp.2009.06.008

Frankl, V. (1964). The image of man of psychotherapy. In M. Friedman (Eds.), The worlds of Existentialism (pp. 462-468). New York, NY: Random House.

Fromm, E. (1950). Psychoanalysis and und Religion. New Haven: Yale University Press.

Gall, T. L., Charbonneau, C., et al. (2011). The relationship between religious/spiritual factors and perceived growth following a diagnosis of breast cancer. Psychology \& Health, 26, 287-305. doi:10.1080/08870440903411013

Gorsuch, R. L. (1997). Exploratory factor analysis: Its role in item analysis. Journal of Personality Assessment, 68, 532-560. doi:10.1207/s15327752jpa6803_5

Grossman, P., Niemann, L., et al. (2004). Mindfulness-based stress reduction and health benefits. A meta-analysis. Journal of Psychosomatic Research, 57, 35-43. doi:10.1016/S0022-3999(03)00573-7

Grossmann, K. E., \& Grossmann, K. (2007). The development of psychological security in attachment-Results and conclusions for therapy [Die Entwicklung psychischer Sicherheit in Bindungen-Ergebnisse und Folgerungen für die Therapie]. Zeitschrift für Psychosomatische Medizin und Psychotherapie, 53, 9-28.

Hall, R. (2010). Intervention with Muslim Filipino families: The implications of spirituality for psychology. Psychology, 1, 45-49. doi:10.4236/psych.2010.11007

Hardt, J., Petrak, F., et al. (2003). What does the FKV measure? An examination of the Freiburger Fragebogen zur Krankheitsverarbeitung in patients with varying diseases [Was misst der FKV? Eine Überprüfung des Freiburger Fragebogens zur Krankheitsverarbeitung bei Patienten mit unterschiedlichen Erkrankungen]. Zeitschrift für Klinische Psychologie und Psychotherapie, 32, 41-50. doi:10.1026//1616-3443.32.1.41

Heszen-Niejodek, I. (2003). Illusory assumptions of self-report questionnaires. [Iluzorycznosc zalozen kwestionariuszy samoopisowych] In M. Fajkowska-Stanik, K. Drat-Ruszczak, \& M. Marsza-Wisniewska (Eds.), Methodological traps in empirical studies [Pulapki metodologiczne w badaniach empirycznych] (pp. 50-59). Warzawa: Academica Wydawnictwo SWPS.

Idler, E. L., Musick, M. A., et al. (2003). Measuring multiple dimensions of religion and spirituality for health research. Research on Aging, 25, 327-365. doi:10.1177/0164027503025004001
Ishida, R., \& Okada, M. (2011). Factors influencing the development of "purpose in life" and its relationship to coping with mental stress. Psychology, 2, 29-34. doi:10.4236/psych.2011.21005

James, A., \& Wells, A. (2003). Religious orientation and mental health: towards a cognitive behavioural framework. British Journal of Health Psychology, 8, 359-376. doi:10.1348/135910703322370905

Kabat-Zinn, J. (1990). Full catastrophe living: Using the wisdom of your body and mind to face stress, pain and illness. New York, NY: Delacorte.

Koenig, H. G., McCullough, M. E., et al. (2001). Handbook of religion and health. Oxford: Oxford University Press. doi:10.1093/acprof:oso/9780195118667.001.0001

Koenig, H. G., Parkerson Jr., G. R., et al. (1997). Religion index for psychiatric research. American Journal of Psychiatry, 154, 885-886.

Kohls, N. S., \& Walach, S. (2009). Facets of mindfulness-Results of an online study investigating the Freiburg mindfulness inventory. Personality and Individual Differences, 46, 224-230. doi:10.1016/j.paid.2008.10.009

Kohr, H. U. (1976). ITAMIS. A user oriented Fortran-program for testand questionnaire analysis [ITAMIS. Ein benutzerorientiertes Fortran-Programm zur Test- und Fragebogenanalyse]. Berichte aus dem Sozialwissenschaftlichen Institut der Bundeswehr.

Lakey, C. E., Campbell, W. K., et al. (2007). Dispositional mindfulness as a predictor of the severity of gambling outcomes. Personality and Individual Differences, 43, 1698-1710. doi:10.1016/j.paid.2007.05.007

Lawler-Row, K. A., \& Elliott, J. (2009). The role of religious activity and spirituality in the health and well-being of older adults. Journal of Health Psychology, 14, 43-52. doi:10.1177/1359105308097944

Moberg, D. O. (2005). Research in spirituality, religion and aging. Journal of Gerontological Social Work, 45, 11-40. doi:10.1300/J083v45n01_02

Mofidi, M., Devellis, R. F., et al. (2006). Spirituality and depressive symptoms in a racially diverse US sample of community-dwelling adults. Journal of Nervous and Mental Disease, 194, 975-977. doi:10.1097/01.nmd.0000243825.14449.de

Mofidi, M., DeVellis, R. F., et al. (2007). The relationship between spirituality and depressive symptoms: Testing psychosocial mechanisms. Journal of Nervous and Mental Disease, 195, 681-688. doi:10.1097/NMD.0b013e31811f4038

Mohr, S., Huguelet, P. (2004). The relationship between schizophrenia and religion and its implications for care. Swiss Medical Weekly, 134, 369-376.

Monod, S., Brennan, M., Rochat, E., Martin, E., Rochat, S., \& Bula, C.J. (2011). Instruments measuring spirituality in clinical research: A systematic review. Journal of General Internal Medicine, 26, 13451357. doi:10.1007/s11606-011-1769-7

Nicholson, A., Rose, R., et al. (2010). Associations between different dimensions of religious involvement and self-rated health in diverse European populations. Health Psychology, 29, 227-235. doi:10.1037/a0018036

Schumann, S. (2009). Eysenk and Schumann had a correspondence in the mid 80's about problems in factor analysis. The cited comment was made by Eysenck in one of the letters, Personal Communication.

Suzuki, D. T., Fromm, E., et al. (1974). Zen-Buddhism and psychoanalysis. Norfolk, Bertrams Print on Demand. [Zen-Buddhismus und Psychoanalyse (1972). Frankfurt, Suhrkamp.]

Walach, H. (2006). Measuring mindfulness-The Freiburg Mindfulness Inventory (FMI). Personality and Individual Differences, 40, 15431555. doi:10.1016/j.paid.2005.11.025

Van Houdenhove, B., \& Luyten, P. (2011). Listen to the story: Chronic fatigue syndrome patients do not live in a vacuum. Psychother Psychosom, 80, 113-115. doi:10.1159/000320974

Worthington Jr., E. L., J. N. Hook, et al. (2011). Religion and spirituality. Journal of Clinical Psychology, 67, 204-214. doi:10.1002/jclp.20760 